\title{
Revo-i assisted robotic central pancreatectomy
}

\author{
Gayoon $\mathrm{Ku}^{1}$, Incheon $\mathrm{Kang}^{2}$, Woo Jung Lee ${ }^{1,3}$, and Chang Moo Kang ${ }^{1,3}$ \\ ${ }^{1}$ Division of HBP Surgery, Department of Surgery, Yonsei University College of Medicine, Seoul, \\ ${ }^{2}$ Division of Hepatobiliary and Pancreatic Surgery, Department of Surgery, \\ CHA Bundang Medical Center, CHA University, Seongnam, \\ ${ }^{3}$ Pancreatobiliary Cancer Center, Yonsei Cancer Center Severance Hospital, Seoul, Korea
}

\begin{abstract}
Central pncreatectomy $(\mathrm{CP})$ can be one of procedures for function-preserving pancreatectomy for patients with benign or low grade malignant pancreatic tumors. Surgeons have to deal with two cut surface of the pancreas when performing $\mathrm{CP}$, which can be associated with severe complication, such as postoperative pancreatic fistula. Fine and delicate surgical skill is highly required for safe CP. With the advance of minimally invasive surgery, CP is now thought to be one of appropriate procedures for function-preserving minimally invasive pancreatectomy. Robotic surgery is thought to make complicated surgical procedure easy and effective. Recently, Korean robotic surgical system, Revo-i, was successfully developed by Meeraecompany and have been proved its safety and feasibility in several recent reports. A 56-year old woman was referred for a body of pancreatic lesion. Contrast abdominopelvic CT revealed a pancreatic body tumor measuring around $1.2 \mathrm{~cm}$ in diameter. The patient underwent a robot-assisted central pancreatectomy using Revo-i. The patient endured the procedure well and was discharged to home at postoperative day 9 . This report showed a successful case of central pancreatectomy performed with the Korean robotic surgical system Revo-i. (Ann Hepatobiliary Pancreat Surg 2020;24:547-550)
\end{abstract}

Key Words: Robotic surgical system; Central pancreatectomy; Robot surgery

\section{INTRODUCTION}

Central pncreatectomy (CP) was rare surgical procedure. Many pancreatic surgeons hesitated CP because they have to deal with two cut surface of the pancreas, which can be associated with severe complication, such as postoperative pancreatic fistula (POPF). ${ }^{1,2}$ In fact, POPF after $\mathrm{CP}$ is reported to be high, up to $41 \%{ }^{2,3}$ However, with the advance of minimally invasive surgery, CP is now thought to be one of appropriate procedures for functionpreserving minimally invasive pancreatectomy. Unlike usual pancreatic cancer, patients with pancreatic benign and low grade malignant neoplasms can be expected for long-term survival. Therefore, their quality of life should be also considered when planning treatment options for them. There are literatures reporting minimally invasive $\mathrm{CP}$ is safe and effective in preserving exocrine and endocrine pancreatic function. ${ }^{4-7}$

For CP, remnant pancreas should be managed following segmental resection of the pancreas. Most potential candidates for CP are benign and low grade malignant neoplasm, which usually have soft remnant pancreas with very small pancreatic duct after limited resection of the pancreas. In addition, some anatomical circumstances are a little different from those in pancreticoduodenectomy (PD, Table 1). Comparing to remnant pancreas in $\mathrm{PD}$, pancreatic duct size is much smaller, and splenic artery is embedded into the pancreas, which is very difficult to take a secure suturing without vascular damage. Therefore, precise and advanced surgical techniques are essential in managing remnant pancreas when performing CP. Especially, laparoscopic pancreatico-jejunostomy, or pancreatico-gastrostomy is technically very difficult to perform due to fundamental disadvantages of laparoscopic surgery.

Received: March 25, 2020; Revised: June 16, 2020; Accepted: June 17, 2020

Corresponding author: Chang Moo Kang

Division of Hepatobiliary and Pancreatic Surgery, Department of Surgery, Yonsei University College of Medicine, 50 Yonsei-ro, Seodaemun-gu, Seoul 03722, Korea

Tel: +82-2-2228-2100-3, Fax: +82-2-313-8289, E-mail: CMKANG@yuhs.ac

Copyright (C) 2020 by The Korean Association of Hepato-Biliary-Pancreatic Surgery

This is an Open Access article distributed under the terms of the Creative Commons Attribution Non-Commercial License (http://creativecommons.org/ licenses/by-nc/4.0) which permits unrestricted non-commercial use, distribution, and reproduction in any medium, provided the original work is properly cited. Annals of Hepato-Biliary-Pancreatic Surgery • pISSN: 2508-5778 - elSSN: 2508-5859 
Therefore, fine and delicate surgical skill is highly required for safe $\mathrm{CP}$.

Robotic surgical system has been introduced to overcome limitation of laparoscopic surgery. Robotic surgery is thought to make complicated surgical procedure easy and effective. Recently, meeraecompany (Korea) successfully develop Korean robotic surgical system (Revo-i), which is very similar to the current da Vinci system (Fig. 1). ${ }^{8,9}$ Several recent reports suggested safety and feasibility of Revo-i in clinical application of minimally invasive surgery. ${ }^{8-11}$

Last year, in 2018, we performed the first Revo-i pancreaticoduodenectomy, showing the potential feasibility and safety of Revo-i in far advanced minimally invasive surgery. ${ }^{12}$ The present case is another story to demonstrate clinical usability of Revo-i in far advanced minimally invasive pancreatectomy. In this case, we report a success-

Table 1. Considering points in dealing with remnant pancreas during PD and CP

\begin{tabular}{lll}
\hline & \multicolumn{1}{c}{ PD } & \multicolumn{1}{c}{ CP } \\
\hline $\begin{array}{l}\text { Texture of } \\
\text { the remnant pancreas }\end{array}$ & Soft/hard & Soft \\
$\begin{array}{l}\text { Pancreatic duct, size } \\
\text { Pancreatic duct, location at }\end{array}$ & $\begin{array}{l}\text { Small/large } \\
\text { Lower, } \\
\text { cut surface }\end{array}$ & $\begin{array}{l}\text { Smaller } \\
\text { Middle or } \\
\text { upper, center } \\
\text { Distances between }\end{array}$ \\
$\begin{array}{l}\text { splenic artery from } \\
\text { remnant pancreas }\end{array}$ & Far & \\
$\begin{array}{c}\text { Cut surface area of } \\
\text { remnant pancreas } \\
\text { (division line location) }\end{array}$ & Small (neck) & Larger (body) \\
\hline
\end{tabular}

ful Revo-i assisted robotic CP for neuroendocrine tumor of the pancreas. The current status of Korean robotic surgical system and future perspectives are also discussed.

\section{CASE}

The patient is a 56-year-old female who was screened by computed tomography (CT) scan of abdomen and pelvis for epigastric pain in September 2019 in a local clinic. She had no specific medical histories. On the CT scan, there was about $1.2 \mathrm{~cm}$ sized hyperenhancing lesion in the body of the pancreas (Fig. 2A). All the results of laboratory tests were in normal range including amylase and lipase. Magnetic resonance imaging (MRI) also showed 1 $\mathrm{cm}$ enhancing lesion in the body of the pancreas. There were no vascular encasements, ductal dilatation or distant metastatic lesions. No variations of anatomy around pancreas were found.

She underwent Revo-i assisted robotic central pancreatectomy on December $2^{\text {nd }}, 2019$. Firstly, we performed laparoscopic resection of the tumor (Fig. 2B). After robotic docking to the port sites (Fig. 1C), Revo-i reconstruction including pancreatojejunostomy $(\mathrm{PJ})$. The proximal portion of pancreas was dissected by endo-GIA stapler. Distal portion was dissected by endo-scissor and electrocautry device for bleeding control. PJ was stitched by prolene 4-0 interrupted and a short stent was inserted (Fig. 2C, D). Total operation time was 295 minutes. Estimated blood loss was $50 \mathrm{ml}$.

The lesion proved to be a neuroendocrine tumor. Tumor
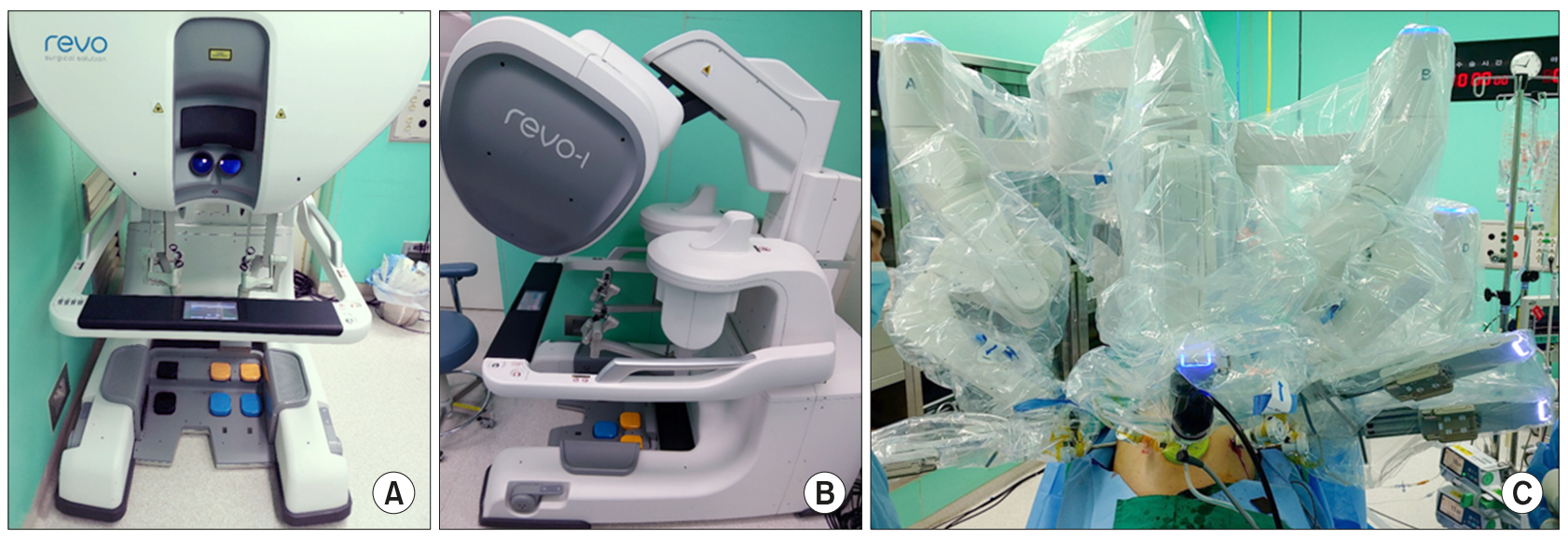

Fig. 1. External view of Revo-i robotic surgical system. (A) Front view of surgical console of Revo-i surgical system. (B) Lateral view of surgical console of Revo-i surgical system. (C) External view after completion of robotic docking to the patient's side ports. 

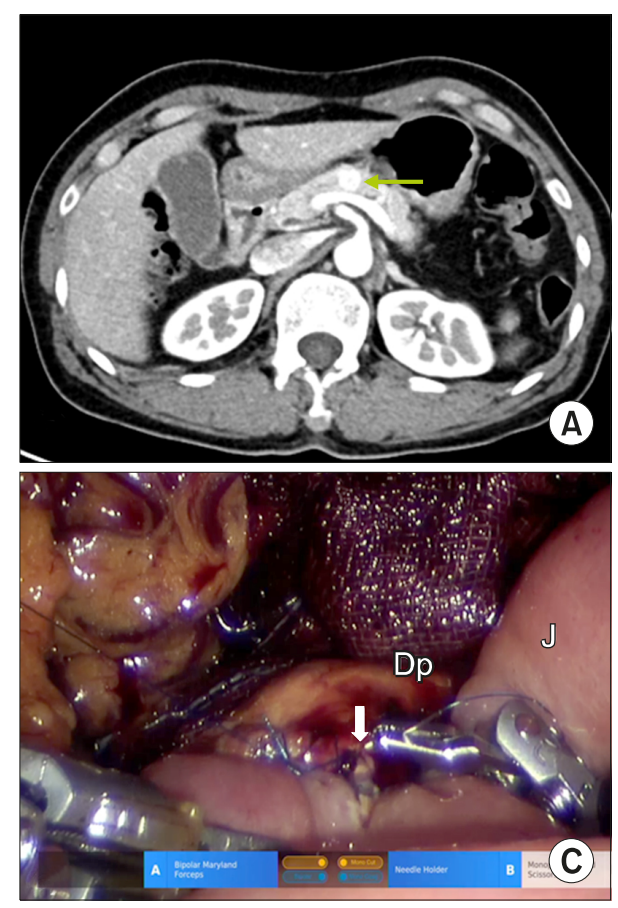
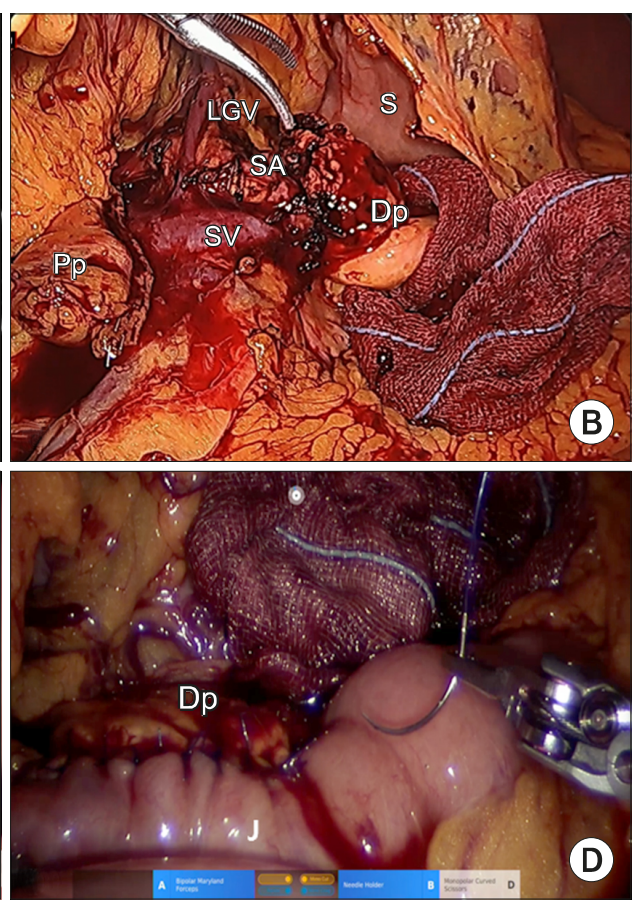

Fig. 2. Preoperative $\mathrm{CT}$ and operative view. (A) Preoperative CT scan. (B) Operation view after laparoscopic resection. (C) Revo-i PJ (duct-to-mucosa), note $1 \mathrm{~mm}$-silicone pancreatic stent (white arrow). (D) Completion of Revo-i PJ. Pp, proximal pancreas; Dp, distal remnant pancreas; SV, splenic vein; LGV, left gastric vein; SA, splenic artery; S, stomach; J, jejunum. size was about $1.0 \times 0.9 \mathrm{~cm}$ and the mitotic count was $0 / 10$ HPF, defined as grade 1 according to 2017 WHO classification*. The lesion was confined to pancreas and all margins were negative from tumor.

The patient endured the procedure well and without complication. Drain was removed postoperative day 7 . Postoperative biochemical POPF was noted. She tolerated more than half of soft meals without any specific symptoms. She was discharged to home at postoperative day 9. There were no other surgical or medical complications.

\section{DISCUSSION}

We have been working on testing clinical feasibility and safety of Revo-i in minimally invasive surgery. Last year, we successfully performed the first Revo-i assisted PD in patients with insulinoma. ${ }^{12}$ At that time, Revo-i was applied for pancreaticojejunostomy (duct-to-mucosa), managing remnant soft pancreas with less than $2 \mathrm{~mm}$ pancreatic duct and choledochojejunostomy after laparoscopic resection of the pancreaticoduodenal unit. In present case of CP, Revo-i was also used for pancreaticojejunostomy (duct-to-mucosa) following laparoscopic segmental resection of the pancreas. However, dealing remnant pancreas in $\mathrm{CP}$ can be much more difficult because there are some anatomical differences between PD and CP (Table 1).
Especially, adjusting the location for duct-to-mucosa anastomosis requires for advanced technical skills for safe laparoscopic surgical procedure. Therefore, robotic surgical system with articulating wrist-like motion of the instrument is very helpful for managing this surgical step. The present case successfully demonstrated that Revo-i can be applicable to PJ with different situations from that of PD during $\mathrm{CP}$.

Based on surgeons' feedback during previous preclinical and clinical trial, ${ }^{8,10}$ meeraecompany tries to improve the quality of Revo-i surgical system. As results, comparing with initial stage of Revo-i, overall surgical system became stable, and coupling capability between movement of surgeon in console and robotic instrument got improved. However, comparing the current da Vinci system, the detailed quality to mechanically transfer surgeon's movement to robot-instrument's motion seems definitely inferior, leaving some engineering issues to be solved in near further. In addition, vision quality also need to be improved and another energy devices needs to be developed.

It is thought that the current da Vinci surgical system is the first wave in era of far advanced minimally invasive surgery. Recently another new version of robotic surgical systems, ${ }^{13}$ including the present Revo-i, has been developed, introduced, and will be applied in real clinical 
practice. Currently, cost-benefit issue of robotic surgical system is regarded as one of the great obstacles to overcome $^{14,15}$ for widely use of robotic surgical system. It is hoped that the current movement can provide more comfortable condition for clinical application of robotic surgical system for safe and effective minimally invasive surgery in near future. The second wave of robotic surgery is coming.

\section{ACKNOWLEDGEMENTS}

This case is one of the patients who underwent Reovo-i pancreatectomy during prospective clinical trial (NCT 04095312).

This study was supported by meeraecompany research grant (IRB No. 1-2019-0030).

The authors especially express their sincere thanks for the robotic surgery-specialized nurses, Soo Young Song, Hyun Jung Song, Jin Ah Chung in Severance Hospital, Seoul, KOREA, whose devotion and helpful comments during the operation enabled us to work on this procedure. Without their active support during Revo-i robotic surgical procedures, this study could not have been conducted.

\section{CONFLICT OF INTEREST}

Some research allowance was provided from the research fund during clinical trial.

\section{ORCID}

Gayoon Ku: https://orcid.org/0000-0003-2051-3201

Incheon Kang: https://orcid.org/0000-0003-4236-5094

Woo Jung Lee: https://orcid.org/0000-0001-9273-261X

Chang Moo Kang: https://orcid.org/0000-0002-5382-4658

\section{AUTHOR CONTRIBUTIONS}

Conceptualization: GK. Data curation: GK, IK, WJL, CMK. Formal analysis: GK. Methodology: GK, CMK. Pro- ject administration: GK, CMK. Visualization: GK. Writing original draft: GK, CMK. Writing - review \& editing: GK, CMK.

\section{REFERENCES}

1. Reber HA. Middle pancreatectomy: why I rarely do it. J Gastrointest Surg 2007;11:730-732.

2. Iacono C, Verlato G, Ruzzenente A, Campagnaro T, Bacchelli C, Valdegamberi A, et al. Systematic review of central pancreatectomy and meta-analysis of central versus distal pancreatectomy. Br J Surg 2013;100:873-885.

3. Kang CM, Lee JM, Kim MW, Yoon DS, Park JS, Lee WJ. Experiences in central pancreatectomy. Dig Surg 2011;28:57-62.

4. Kang CM, Lee JH, Lee WJ. Minimally invasive central pancreatectomy: current status and future directions. J Hepatobiliary Pancreat Sci 2014;21:831-840.

5. Ronnekleiv-Kelly SM, Javed AA, Weiss MJ. Minimally invasive central pancreatectomy and pancreatogastrostomy: current surgical technique and outcomes. J Vis Surg 2016;2:138.

6. Kang CM, Kim DH, Lee WJ, Chi HS. Initial experiences using robot-assisted central pancreatectomy with pancreaticogastrostomy: a potential way to advanced laparoscopic pancreatectomy. Surg Endosc 2011;25:1101-1106.

7. Hamad A, Novak S, Hogg ME. Robotic central pancreatectomy. J Vis Surg 2017;3:94.

8. Chang KD, Raheem AA, Rha KH. Novel robotic systems and future directions. Indian J Urol 2018;34:110-114.

9. Kang CM, Chong JU, Lim JH, Park DW, Park SJ, Gim S, et al. Robotic cholecystectomy using the newly developed Korean robotic surgical system, Revo-i: a preclinical experiment in a porcine model. Yonsei Med J 2017;58:1075-1077.

10. Lim JH, Lee WJ, Park DW, Yea HJ, Kim SH, Kang CM. Robotic cholecystectomy using Revo-i Model MSR-5000, the newly developed Korean robotic surgical system: a preclinical study. Surg Endosc 2017;31:3391-3397.

11. Chang KD, Abdel Raheem A, Choi YD, Chung BH, Rha KH. Retzius-sparing robot-assisted radical prostatectomy using the Revo-i robotic surgical system: surgical technique and results of the first human trial. BJU Int 2018;122:441-448.

12. Kang I, Hwang HK, Lee WJ, Kang CM. First experience of pancreaticoduodenectomy using Revo-i in a patient with insulinoma. Ann Hepatobiliary Pancreat Surg 2020;24:104-108.

13. Rao PP. Robotic surgery: new robots and finally some real competition! World J Urol 2018;36:537-541.

14. Xu SB, Jia CK, Wang JR, Zhang RC, Mou YP. Do patients benefit more from robot assisted approach than conventional laparoscopic distal pancreatectomy? A meta-analysis of perioperative and economic outcomes. J Formos Med Assoc 2019;118(1 Pt 2):268-278.

15. Souche R, Herrero A, Bourel G, Chauvat J, Pirlet I, Guillon F, et al. Robotic versus laparoscopic distal pancreatectomy: a French prospective single-center experience and cost-effectiveness analysis. Surg Endosc 2018;32:3562-3569. 